\title{
Analgosedation in neonates: what we know and how we act
}

\author{
This article was published in the following Dove Press journal: \\ Research and Reports in Neonatology \\ 20 November 2013 \\ Number of times this article has been viewed
}

\author{
Karel Allegaert ${ }^{1,2}$ \\ Carlo V Bellieni ${ }^{3}$ \\ 'Department of Development and \\ Regeneration, ${ }^{2} \mathrm{KU}$ Leuven and \\ Neonatal Intensive Care Unit, \\ University Hospitals Leuven, Belgium; \\ ${ }^{3}$ Department of Pediatrics, Obstetrics \\ and Reproduction Medicine, \\ University of Siena, Siena, Italy
}

\begin{abstract}
Inadequate pain management in neonatal life impairs the neurodevelopmental outcome. It alters pain thresholds, pain and stress-related behavior, and physiologic responses in later life. At the same time, there are emerging animal experimental and human epidemiologic data on the impact of analgosedatives on neuroapoptosis and impaired neurodevelopmental outcome. As a consequence, the management of neonatal pain is in search of a new equilibrium since these conflicting (undertreatment versus overtreatment) observations are the main drivers of its current management. Such tailoring includes new treatment modalities, and also more effective implementation strategies. The search for tailored nonpharmacologic (ie, less invasive techniques, preventive strategies, complementary techniques) and pharmacologic (eg, dexmedetomidine, intravenous acetaminophen, remifentanil) treatment modalities are discussed and reflect the increased knowledge on neonatal pain management. Despite this increasing knowledge ("toolbox") regarding neonatal pain, there is still a major gap between knowledge ("what we know") and practice ("how we act"). Consequently, more research activity on methods for effective implementation of the available knowledge is needed. Illustrations of effective approaches, eg, the Evidence-Based Practice for Improving Quality (EPIQ) initiative, to bridge this gap are provided. This is followed by an intersubjective proposal on priorities for contemporary clinical management and a research agenda.
\end{abstract}

Keywords: pain, newborn, prevention, guidelines

\section{Introduction}

\section{Why pain management in neonates is of relevance}

Already more than three decades ago, the myth that immaturity precludes neonates from pain perception and its negative effects was rejected by Anand et al when they documented that inadequate perioperative analgesia resulted in higher morbidity and mortality. ${ }^{1}$ Moreover, it became apparent that these negative effects were not limited to neonatal life, but were also observed in later pediatric life and beyond. ${ }^{1-4}$ In essence, adequate analgesia in neonates should not only been driven by empathy or ethics, but is valid, appropriate, and needed medical and nursing care. ${ }^{5}$

More recently, experimental data in animals have provided evidence that perinatal exposure to analgosedatives also results in reduced brain growth, decreased neuronal packing density, and less dendritic growth and branching. ${ }^{6,7}$ This is because of the impact of analgosedatives on axonal growth and apoptosis of neuronal tissue. There seems to be an age-related window of vulnerability for apoptosis or dendritic changes related to human neonatal life and infancy, respectively. These anatomic findings are associated with learning and motor disabilities.
Correspondence: Karel Allegaert Neonatal Intensive Care Unit, University Hospital, Herestraat 49, 3000 Leuven, Belgium

Tel $+32 \quad 16343850$

Fax +32 I634 3209

Email karel.allegaert@uzleuven.be 
Extrapolation of animal experimental observations to the human newborn are obviously limited and mainly based on associations. ${ }^{6-9}$ There are data on an association between major neonatal surgery (number of interventions, disease severity) and neurodevelopmental impairment. However, exposure to analgosedatives is only one of the factors associated with a negative outcome. Obviously, neonates who repeatedly undergo anesthesia during infancy are more likely to have other risk factors for impaired neurodevelopment. At the same time, we know from animal experiments and the clinical studies by Anand et al that surgery without analgesia has a major impact on morbidity and mortality. ${ }^{1,6,7}$

\section{Why pain management in neonates is different}

From the above-mentioned arguments, it is obvious that effective pain management is an important indicator of the quality of care provided to neonates, not only from an ethical standpoint, but also in terms of protecting the long-term outcome. ${ }^{1-9}$ Neonates cannot assert their rights, and their reactions to pain are not so evident as in adults. Moreover, medical treatment initially has a strong focus on saving their lives, accepting that well-being is only secondary.
Now we know that babies are full patients in terms of their rights, and that neonates do feel pain and are even more vulnerable to pain. These more vulnerable neonates are precisely those that are most exposed to painful interventions. Finally, the subjectivity inherent in neonatal pain assessment probably further contributes to the wide variety of practices. All these reasons explain why pain management in neonates warrants a focused, population-tailored, individualized approach related to assessment, treatment, and preventive strategies since all these aspects (assessment, treatment, prevention) have population-specific issues (Figure 1). ${ }^{10}$

\section{Measurement/assessment}

The absence of verbalization is very likely one of the most important obstacles to proper diagnosis, quantification, and treatment of neonatal pain. Pain in the newborn is often not easily recognized and remains commonly undertreated or untreated..$^{10-13}$ In general, if a procedure is painful in adults, it should be considered painful in neonates. Because the pain threshold is lower in the newborn, it is reasonable that pain will be greater in neonates compared with adults for a similar procedure. Newborns depend completely on caregivers (parents, health care professionals) to recognize their needs. This includes aspects related to comfort and stress reduction,

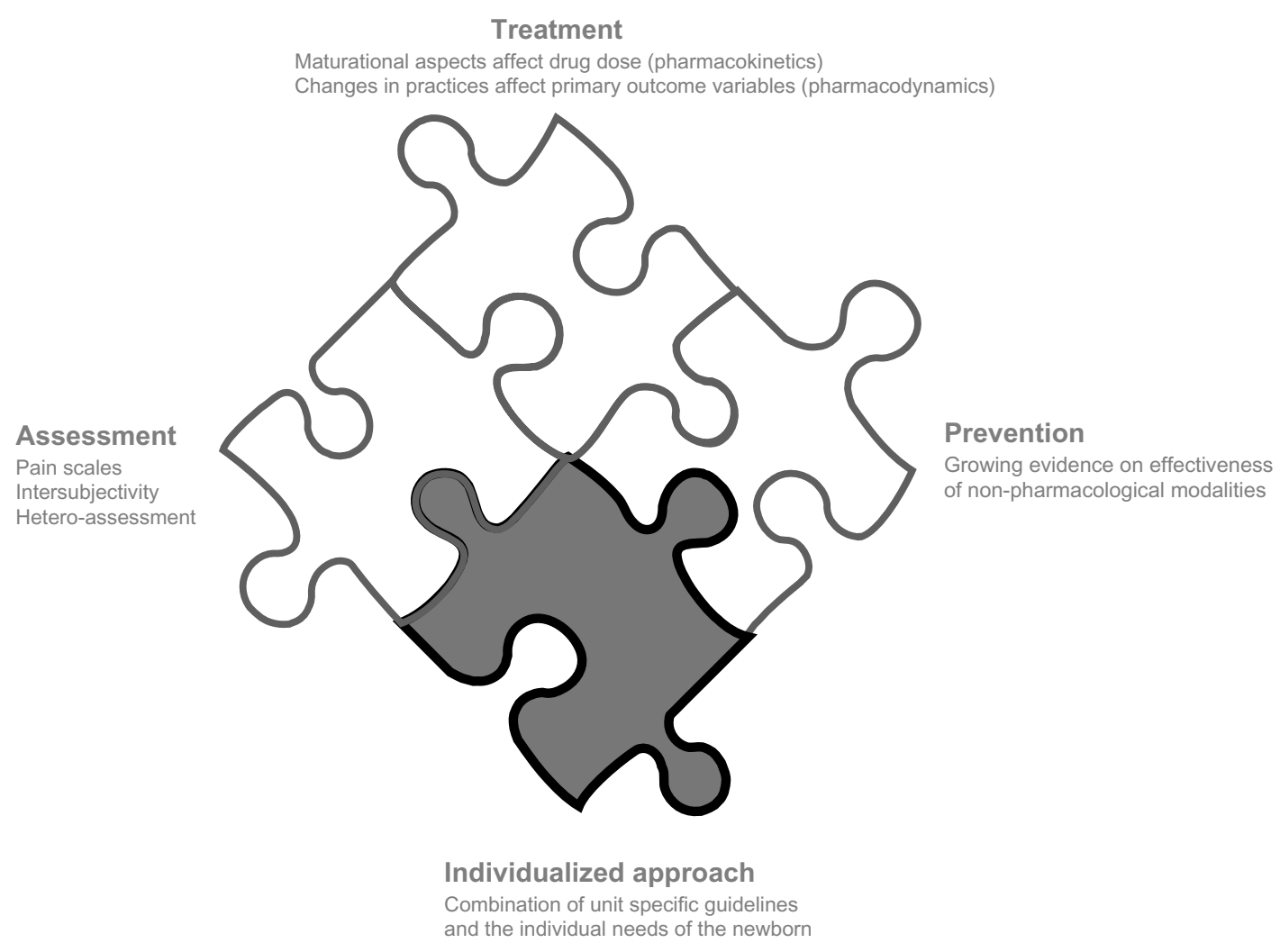

Figure I Why pain management in neonates warrants a focused approach. 
and should cover evaluation/assessment, prevention, and management of pain. ${ }^{4,9}$

\section{Treatment}

When we apply the concept of developmental pharmacology to analgosedatives in neonates, this should be based on systematic assessment (pharmacodynamics, concentrationeffect), titrated administration of the most appropriate analgesia (pharmacokinetics, concentration-time), and reassessment (pharmacodynamics) to adapt and titrate exposure to effects (pharmacodynamics). ${ }^{5}$

Clinical management and subsequent primary pharmacodynamic outcome variables shifted. To illustrate this, respiratory support after surfactant administration (InSuRe [Intubation, Surfactant and Rapid Extubation]) is much more common than prolonged ventilation, and hypothermia has been introduced as an effective tool to treat peripartum asphyxia. ${ }^{9}$ This results in the need for new pharmacokinetic/pharmacodynamic data in new (sub)populations.

\section{Preventive strategies}

Environmental (noise, light), behavioral (positioning) and nonpharmacologic (sucrose, breastfeeding, pacifier) interventions can prevent, reduce, or eliminate pain and may improve comfort. Such interventions need to be validated first, and subsequently compared and integrated in routine care. ${ }^{14-17}$ Following validation, emphasis should be placed on integration. Promotion of clinical research, diffusion of knowledge, and validation of the effectiveness of implementation strategies to improve analgosedation remain crucial. $^{14-17}$

\section{Despite this, we do not stick to the guidelines}

Despite ethical issues, increasing awareness, and the availability of guidelines on procedural pain, neonates still often experience avoidable pain. ${ }^{18}$ The discrepancy between the available knowledge and clinical practice has been reillustrated by Carbajal et al. ${ }^{19}$ Epidemiologic data on the incidence of painful procedures and their management during the first 14 days of admission were prospectively collected over a 6-week period (2005-2006) in 430 neonates admitted to tertiary care neonatal intensive care units in the Paris region of France. Of 42,413 painful procedures identified, 2.1\% were performed with pharmacologic therapy only, $18.2 \%$ with nonpharmacologic therapy only, $20.8 \%$ with pharmacologic and nonpharmacologic therapy, and $79.2 \%$ without specific analgesia; $34.2 \%$ were performed while the neonate was receiving concurrent analgesic or anesthetic infusions for other reasons. Consequently, the investigators concluded that large numbers of procedures were performed and most were not accompanied by analgesia. ${ }^{19}$ These findings are unfortunately very similar to the data published by Simons et al and collected 5 years earlier. ${ }^{20}$ In their dataset comprising 151 preterm neonates, each neonate was subjected to $14 \pm 4$ procedures per day. Pre-emptive analgesia was provided to less than $35 \%$ of these neonates, and about $40 \%$ did not receive any analgesic therapy during their stay in the neonatal intensive care unit. ${ }^{20}$

Similar results were reported when practices were compared between two time intervals in the same region. ${ }^{21,22}$ Survey data on analgesia policy and practices for common invasive procedures at Italian neonatal intensive care units were compared for the years 2004 and 2010 to ascertain the extent to which neonatal analgesia for invasive procedures has changed since publication of the Italian guidelines. According to paired data from 75 neonatal intensive care units, the practice of pain monitoring has become more common. However, only $21 \%$ and $17 \%$ of neonatal intensive care units routinely assessed pain during mechanical ventilation and after surgery, respectively. Similarly, routine use of medication for major invasive procedures was still limited (35\% of lumbar punctures, $40 \%$ of tracheal intubations, $46 \%$ during mechanical ventilation) and postoperative pain treatment was also inadequate. Consequently, the authors concluded that despite the improvements in neonatal analgesia practices in Italy since the national guidelines were published, pain is still largely undertreated and underscored in this age group. ${ }^{21,22}$ Similar conclusions can be drawn when we focus on pain management during a specific procedure (heel lancing, Europe), ${ }^{23}$ or on pain assessment (Sweden). ${ }^{24}$ At the least, there is still room for improvement.

This review illustrates the progress made in the search for better tailored nonpharmacologic and pharmacologic interventions, without being a systematic review of all studies reported on such interventions in neonates. Tailored nonpharmacologic interventions focus on less invasive techniques, preventive strategies, and complementary techniques. Tailored pharmacologic interventions focus on new compounds (dexmedetomedine, intravenous acetaminophen, remifentanil). In addition to providing additional knowledge on neonatal pain management, we also focus on the need to do more research regarding methods for effective implementation of such knowledge. This is because there is still a gap between knowledge (what we know) and practice (how we act). Illustrations of effective approaches to bridge this 
gap, eg, the Evidence-Based Practice for Improving Quality (EPIQ) initiative and care bundles, will be provided. This is followed by an intersubjective proposal on priorities for contemporary clinical management and a research agenda.

\section{Tailored nonpharmacologic treatment: intensive "care" in addition to intensive "cure" Not only what but also how we perform procedures matters}

Environmental (noise, light), behavioral (positioning), and nonpharmacologic (sucrose, breastfeeding, pacifier) interventions can prevent, reduce, or eliminate pain, and may improve comfort. Adaptations of procedural techniques or practices may be a very powerful method of preventing pain and reducing stress. ${ }^{916,17}$ Such strategies include light and noise reduction, nesting or swaddling, minimizing patient handling (eg, preserving free periods for sleep, avoiding consecutive blood sampling, clustered care), use of central venous catheters instead of multiple peripheral perfusions, individualized monitoring techniques (registration of vital signs, blood pressure measurement intervals), tailoring nursing techniques (eg, frequency of endotracheal suctioning, skin and wound care, tape and wound dressing), and promoting skin-to-skin contact between newborns and parents. In essence, methods matter, and adaptations of existing techniques can be very effective in reducing pain. The available evidence is illustrated based on published data related to venous blood sampling and endotracheal suctioning in neonates.

Venous blood sampling is commonly performed in neonates. In addition to complementary interventions like non-nutritive sucking, sucrose, or containment, the technique used for blood sampling is also of relevance, as shown in two studies including 120 and 100 healthy term neonates. In the study by Larsson et al, venepuncture by needle was compared with either a small or large lancet (heel lancing). ${ }^{25}$ Sampling with only one skin puncture was successful in $86 \%$ (needle puncture), $19 \%$ (small), and 40\% (large lancet) of cases, and median time for collection was 191, 419, and 279 seconds, respectively. Lower pain (Neonatal Facial Coding) scores were recorded in the needle group than using either of the heel lancing techniques. Similar observations were reported in a study by Ogawa et $\mathrm{al}^{26}$ in which 100 healthy term neonates were randomly allocated one of four groups (venepuncture versus heel lancing, oral sucrose versus water). Using this design, the Neonatal Facial Coding score was significantly lower in the venepuncture group (230 versus 580 ). Interest- ingly, the lancing with sucrose group still had higher scores compared with the venepuncture without sucrose group (470 versus 230).

Endotracheal suctioning is also a stressful procedure, commonly associated with pronounced fluctuations in vital signs. Cordero et al compared two endotracheal suctioning frequencies in preterm neonates and concluded that there was no benefit of systematic routine suctioning when compared with suctioning as needed. ${ }^{27}$ Based on these findings, an evidence-based protocol whereby ventilated newborns were suctioned only as needed according to clinical indicators was developed. This protocol was subsequently introduced as part of a collaborative quality improvement initiative $e^{28}$ and resulted in a significant decrease in the number of procedures performed. ${ }^{29}$

In addition to frequency of suctioning, procedural adaptations (disconnection, deep versus shallow) may also reduce distress. There is evidence to suggest that endotracheal suctioning without disconnection improves the short-term outcome when focusing on vital signs, likely reflecting a reduced stress response. ${ }^{30}$ In contrast, there is no evidence of the benefits or risks of deep versus shallow suctioning of endotracheal tubes in ventilated neonates. ${ }^{31}$ Disconnection and deep versus shallow endotracheal suctioning have been evaluated in two recent Cochrane meta-analyses. ${ }^{30,32}$ Using a crossover design in 252 infants to compare endotracheal suctioning with or without disconnection, suctioning without disconnection resulted in a reduction in both frequency and severity of hypoxic events. ${ }^{30}$ Similarly, endotracheal suctioning without disconnection resulted in a more limited change in heart rate. The number of infants having bradycardic events was also reduced during closed suctioning. Interestingly, four-handed care to facilitate containment during endotracheal suctioning also resulted in a significant decrease in stress and defense behavior. ${ }^{33}$

\section{Add-on value of nonpharmacologic interventions}

Awareness of the persistently high number of painful procedures performed, combined with concerns regarding the potential adverse effects of drugs and perhaps also the aim to involve parents, has resulted in evaluation of alternative, nonpharmacologic interventions in neonates. ${ }^{1-10}$ Nonpharmacologic interventions have wide applicability for neonatal pain management alone or in combination with pharmacologic treatments. These interventions are not necessarily substitutes for or alternatives to pharmacologic interventions, but are complementary. Nonpharmacologic interventions can reduce neonatal pain indirectly by reducing 
the total amount of noxious stimuli and directly by blocking nociceptive transduction or transmission, activation of descending inhibitory pathways, or by activating attention and arousal systems that modulate pain. Non-nutritive sucking, providing sucrose, glucose, or human milk, swaddling and containment procedures, sensory stimulation, and kangaroo care are complementary interventions. ${ }^{33-37}$ Some of the available evidence on the benefit for analgosedation in neonates is summarized here.

\section{Non-nutritive sucking}

There is limited evidence on the use of non-nutritive sucking as a single intervention to promote behavioral outcomes and gastrointestinal function or feeding tolerance in preterm and high-risk full-term infants, but it has been linked to a reduced length of hospital stay and improved pain management. ${ }^{34,35}$ Non-nutritive sucking does not appear to have any short-term negative effects, but data on long-term outcome are not available. For procedural pain management, pacifiers reduce pain scores in neonates. ${ }^{33,34}$

\section{Sucrose, glucose, and human milk}

The most extensively evaluated nonpharmacologic intervention for procedural pain relief in neonates is oral sucrose $(12 \%-24 \%)$, glucose $(30 \%)$, or mother's milk, with or without non-nutritive sucking (pacifier). It is believed that the effects of sucrose and non-nutritive sucking are mediated by both the endogenous opioid and nonopioid systems. ${ }^{33-37}$ There is metaanalytical evidence in support of the use of oral sucrose $24 \%$, glucose $30 \%$, or mother's milk in combination with a pacifier shortly before a painful procedure (eg, blood sampling, nasogastric tube placement, immunization/vaccination). ${ }^{35-37} \mathrm{Com}-$ pared with topical anesthesia, acetaminophen, or morphine, glucose/sucrose resulted in the most prominent decrease in pain during heel prick procedures. ${ }^{35-37}$ Consequently, this became the most commonly used intervention for procedural analgesia in neonates. To make it more effective, this should be combined with use of a pacifier and the sweet solution should be administered on the tongue shortly ( 2 minutes) before the start of the intervention. ${ }^{33-37}$ This time interval is thought to reflect endogenous opioid release. Interestingly, breastfeeding in addition to holding and skin-to-skin contact provided superior analgesia during heel prick when compared with sucrose with or without skin-to-skin contact. ${ }^{37}$

\section{Swaddling and containment}

Preterm infants show improved neuromuscular development, less physiologic distress, better motor organization, and more self-regulatory ability when swaddled. When compared with massage alone, excessively crying infants cried less when swaddled. In neonatal intensive care units, the data are somewhat more contradictory. In meta-analysis, it seems that swaddling has a pain-reducing effect, maintained for longer in term neonates than in preterm neonates. ${ }^{38}$ Because the primary outcomes of studies related to swaddling and containment are less commonly summarized, an illustrative overview of studies on facilitated tucking in of (pre)term neonates (either or not combined or compared with other complementary interventions) is provided in Table $1 .{ }^{37,39-48}$ Most of these studies were not blinded, had a crossover design, and order effects are rarely reported. However, the available evidence suggests a modest reduction in pain with a faster return of physiologic fluctuations to baseline. Facilitated tucking alone was less effective when compared with use of sucrose. However, facilitated tucking in combination with sucrose had an added value (ie, synergism) in the recovery phase, with lower pain scores compared with both single interventions. ${ }^{45}$ The same synergism concept has been documented when combining breastfeeding with skin-to-skin contact for analgesia during heel prick. ${ }^{37}$

\section{Multisensorial stimulation and sensorial saturation} Sensorial saturation refers to multisensorial stimulation consisting of simultaneous delicate tactile, gustative, auditory, and visual stimuli. ${ }^{43}$ This procedure consists of simultaneously attracting the infant's attention by massaging the infant's face; speaking to the infant gently but firmly, and instilling a sweet solution on the infant's tongue. Nonpainful stimulation by engaging a number of channels (ie, auditory, tactile, visual, vestibular, gustatory) is thought to compete with the painful sensory input. In a recent systematic review on this topic, ten studies were retrieved that had evaluated at least partial sensorial saturation. Based on the evidence collected, the use of an oral solution alone seemed to be less effective than sensorial saturation, while sensorial stimulation without a sweet oral solution was ineffective. ${ }^{49}$ Consequently, it was concluded that sensorial saturation could be used for newborns undergoing minor painful procedures. It is more effective than oral sugar alone and promotes interaction between the caregiver and infant.

\section{Tailored pharmacologic treatment modalities}

When the concepts of neonatal pharmacology are applied to neonatal analgosedation, they should be based on systematic assessment, followed by correct (eg, titrated administration, 
Table I Studies on facilitated tucking combined or compared with other complementary interventions

\begin{tabular}{|c|c|}
\hline Reference & Study design \\
\hline Corff et al ${ }^{39}$ & $\begin{array}{l}\text { Randomized crossover study in } 30 \text { preterm neonates ( } 25-35 \text { weeks) to compare the effects of facilitated tucking with those of } \\
\text { routine care on vital signs and sleep disruption after heel lancing. Facilitated tucking resulted in a lower heart rate, a shorter crying } \\
\text { time, and less sleep disruption. }\end{array}$ \\
\hline Fearon et $\mathrm{al}^{40}$ & $\begin{array}{l}\text { Responses of } 15 \text { preterm neonates to swaddling after a heel lance were quantified. Protracted behavioral disturbances were } \\
\text { reduced by swaddling. }\end{array}$ \\
\hline $\begin{array}{l}\text { Ward-Larson } \\
\text { et al }{ }^{41}\end{array}$ & $\begin{array}{l}\text { Randomized crossover study in } 40 \text { preterm neonates ( } 23-32 \text { weeks) to assess the impact of facilitated tucking (second nurse) on } \\
\text { pain related to endotracheal suctioning. Pain expression during facilitated tucking was significantly lower. }\end{array}$ \\
\hline Hill et $\mathrm{al}^{42}$ & $\begin{array}{l}\text { Randomized crossover study in } 12 \text { preterm neonates ( } 25-34 \text { weeks) to compare the impact of facilitated tucking with routine care } \\
\text { on the stress response during routine nursing assessments. Nine of I } 2 \text { infants received a lower PIPP score with facilitated tucking. }\end{array}$ \\
\hline Axelin et $\mathrm{al}^{43}$ & $\begin{array}{l}\text { Prospective, randomized controlled trial in } 20 \text { preterm neonates ( } 24-33 \text { weeks) to assess the impact of facilitated tucking by } \\
\text { parents on pain expression (NIPS) and vital signs during endotracheal/pharyngeal suctioning. Facilitated tucking resulted in a lower } \\
\text { NIPS (median 3-5) score. }\end{array}$ \\
\hline Liaw et $\mathrm{al}^{44}$ & $\begin{array}{l}\text { Randomized, controlled crossover trial in } 34 \text { preterm neonates ( } 29-37 \text { weeks) to compare non-nutritive sucking with facilitated } \\
\text { tucking and routine care on pain response after heel lancing. Both facilitated tucking and non-nutritive sucking resulted in a reduced } \\
\text { pain response, but non-nutritive sucking was more effective. }\end{array}$ \\
\hline $\begin{array}{l}\text { Cignacco } \\
\text { et } \mathrm{al}^{45}\end{array}$ & $\begin{array}{l}\text { Randomized controlled trial in } 7 \mathrm{I} \text { neonates ( } 24-32 \text { weeks) to assess the effect of sucrose, facilitated tucking, or both, on the pain } \\
\text { response following heel lancing. Facilitated tucking was less effective compared with sucrose. Combination of both interventions } \\
\text { resulted in synergism. }\end{array}$ \\
\hline Liaw et $\mathrm{al}^{46}$ & $\begin{array}{l}\text { Randomized controlled trial to assess the impact of non-nutritive sucking, sucrose, and facilitated tucking either alone or combined } \\
\text { on sleep-wake states after heel lancing in } 110 \text { infants (gestational age } 26.4-37 \text { weeks). Combined non-nutritive sucking, sucrose, } \\
\text { and facilitated tucking resulted in the best preservation of the infant's sleep-wake states. }\end{array}$ \\
\hline $\begin{array}{l}\text { Sundaram } \\
\text { et al }{ }^{47}\end{array}$ & $\begin{array}{l}\text { Randomized, controlled, crossover pilot study in } 20 \text { preterm neonates ( } 28-36 \text { weeks) to compare the impact of facilitated tucking } \\
\text { with no intervention after heel lancing. Facilitated tucking resulted in significantly lower pain scores. }\end{array}$ \\
\hline Gerull et $\mathrm{al}^{48}$ & $\begin{array}{l}\text { Compare the influence of facilitated tucking, sucrose, or both on cortical activation, heart rate, and peripheral oxygen saturation } \\
\left(\mathrm{SaO}_{2}\right) \text { after } 125 \text { heel lancing procedures. Sucrose was more effective in reducing the reaction to pain than facilitated tucking. } \\
\text { Application of both interventions had no additive effect. }\end{array}$ \\
\hline $\begin{array}{l}\text { Marin Gabriel } \\
\text { et al }^{37}\end{array}$ & $\begin{array}{l}\text { Breastfeeding with skin-to-skin contact, compared with sucrose with or without skin-to-skin contact during heel lancing. } \\
\text { Breastfeeding with skin-to-skin contact provided superior analgesia when compared with both individual interventions. }\end{array}$ \\
\hline
\end{tabular}

Abbreviations: NIPS, Neonatal Infant Pain Scale; PIPP, Premature Infant Pain Profile.

loading dose) administration of the most appropriate analgosedative (eg, effects/side effects) with subsequent reassessment of the newborn and, if indicated, further adaptation (eg, increase, decrease, synergism). ${ }^{5,9}$ We aim to illustrate the progress made based on aspects of the pharmacokinetics and pharmacodynamics of specific newly emerging compounds (dexmedetomidine, intravenous paracetamol, remifentanil) in neonates. Although these compounds have "dripped" into our units, we need to be aware that the evidence in support of these newer compounds is still limited.

\section{Dexmedetomidine}

Optimal analgosedation is rapid in onset, predictable, unrelated to active metabolites, and shows rapid dissipation of effects on discontinuation. Preferably, the drug is nonaddictive (physical dependence or withdrawal on discontinuation), and without tolerance or adverse effects. ${ }^{9,50}$ Dexmedetomidine may become a potentially useful compound to attain this in neonates. Dexmedetomidine is a strongly lipophilic $\alpha 2$-adrenoreceptor agonist with a $\alpha 2 / \alpha 1$ activity ratio of $1,620 / 1$. Its mechanism of action is via G-protein activation central postsynaptic $\alpha 2$-adrenoreceptors, leading to inhibition of norepinephrine release, resulting in sedative, analgesic, opioid-sparing, and anxiolytic properties, as well as side effects such as hypotension or bradycardia. ${ }^{50,51}$

Dexmedetomidine has many claimed theoretical advantages over standard sedatives with regard to adverse drug reactions and does not affect respiratory drive. ${ }^{52-54}$ At present, clinical experience with dexmetomidine in neonates is only anecdotal. ${ }^{51}$ However, it holds promise as a useful tool for analgosedation in neonates. ${ }^{50-54}$ Data are not yet available to formulate any recommendation, except for the fact that this drug should only be used in clinical studies to obtain valid data on the risk/benefit profile in neonates.

\section{Acetaminophen}

Acetaminophen is the most commonly prescribed drug for mild to moderate pain, including in neonates. In addition to enteral formulations, intravenous formulations are available. Such formulations enable administration when the enteral route cannot (yet) be used and should improve predictability by reducing variability in absorption. ${ }^{55}$ The effect 
compartment concentration for acetaminophen of $10 \mathrm{mg} / \mathrm{L}$ is achieved following administration of a loading dose. ${ }^{56,57}$ Compared with opioids, tolerance does not develop during repeated administration, but there is an analgesic ceiling effect. ${ }^{56,57}$ Based on these facts, the concept of multimodal analgesia has been introduced in neonatal intensive care. Very recently, Ceelie et al documented a clinically relevant and significant $(-66 \%)$ morphine-sparing effect in neonates cotreated with intravenous acetaminophen following major noncardiac surgery, thereby documenting the validity of multimodal analgesia in neonates. ${ }^{58}$

In contrast, acetaminophen has a limited analgesic effect for procedure-related pain. Shah et al documented that administration of acetaminophen ( $20 \mathrm{mg} / \mathrm{kg}$ orally) was ineffective for pain relief related to heel prick. ${ }^{59}$ The effects of acetaminophen (20 mg/kg rectally) in neonates following vacuum extraction has been documented by Van Lingen et al. ${ }^{60}$ Acetaminophen improved their clinical condition (eg, drinking behavior), but without differences in pain scores. Very recently, using a preemptive approach (ie, in all cases, irrespective of pain score) in 123 term neonates following assisted vaginal delivery, infants born by assisted vaginal delivery had low pain scores in the immediate period after birth, irrespective of acetaminophen exposure. ${ }^{61}$ However, acetaminophen (20-25 mg/kg rectally) given to term newborns shortly after birth was associated with an aggravated subsequent stress response during heel lancing on day 2-3 of postnatal life. ${ }^{61}$

\section{Remifentanil}

Besides morphine and fentanyl, there are also observations on shorter-acting opioids in neonates. Alfentanil, sufentanil, and more recently remifentanil have been evaluated, mainly for short procedures such as endotracheal intubation, retinal laser surgery, or percutaneous intravenous central catheter placement, and there is some anecdotal experience during major surgery or maintaining analgosedation during mechanical ventilation. ${ }^{62}$ Remifentanil hydrochloride is a short-acting $\mu$-receptor opioid agonist. It achieves its peak analgesic effect within a minute of administration, ie, 3-4 times faster when compared with fentanyl and much faster in comparison with morphine. ${ }^{62}$

Table 2 summarizes the studies on endotracheal intubation with remifentanil in neonates, and illustrates the variability in strategies and outcome criteria. ${ }^{63-67}$ There is variability in the clinical characteristics (preterm or term, use of InSuRE, or continuation of ventilation), outcome criteria (intubation score, duration of procedure, physiologic variables), comedication, and doses (1-4 $\mu \mathrm{g} / \mathrm{kg}$ intravenously, slow bolus) evaluated. The total number of neonates exposed to remifentanil in these studies suggests that further studies on dose-seeking and safety are needed. To assess the analgesic and procedural efficacy of low-dose remifentanil infusion during percutaneous central catheter placement in preterm infants, 54 preterm neonates were assigned to remifentanil infusion $(0.03 \mu \mathrm{g} / \mathrm{kg}$ per minute) or placebo in addition to $0.3 \mathrm{~mL}$ of $12 \%$ oral sucrose combined with non-nutritive sucking. ${ }^{68}$ Pain scores were significantly lower in neonates exposed to remifentanil, suggesting better pain and distress control without a difference in duration of the procedure. In essence, remifentanil is a very short-acting compound with limited reported experience in neonates at this time. Its pharmacologic profile seems suited for short

Table 2 Studies of remifentanil for endotracheal intubation

\begin{tabular}{|c|c|}
\hline Reference & Study design and results \\
\hline $\begin{array}{l}\text { Pereira e Silva } \\
\text { et } \mathrm{al}^{63}\end{array}$ & $\begin{array}{l}\text { Double-blind, randomized controlled trial in } 20 \text { preterm neonates }(28-34 \text { weeks) to evaluate intubation conditions following } \\
\text { morphine I } 50 \mu \mathrm{g} / \mathrm{kg} \text { or remifentanil I } \mu \mathrm{g} / \mathrm{kg} \text {, both with midazolam } 0.2 \mathrm{mg} / \mathrm{kg} \text {. Overall condition was better in the remifentanil group. }\end{array}$ \\
\hline Welzing et $\mathrm{al}^{64}$ & $\begin{array}{l}\text { Prospective study in } 21 \text { preterm neonates (29-3I weeks) treated with remifentanil } 2 \mu \mathrm{g} / \mathrm{kg} \text { and atropine } 10 \mu \mathrm{g} / \mathrm{kg} \text { for the } \mathrm{InSuRE} \\
\text { procedure. Outcome variables were intubation conditions, time until extubation, and complications. Intubation conditions were } \\
\text { rated as excellent or good. Average extubation time after surfactant was } 16.9 \text { (range I-45) minutes. }\end{array}$ \\
\hline Choong et $\mathrm{al}^{65}$ & $\begin{array}{l}\text { Double-blind, randomized controlled trial in } 30 \text { (pre)term neonates. Remifentanil } 3 \mu \mathrm{g} / \mathrm{kg} \text { was compared with fentanyl } 2 \mu \mathrm{g} / \mathrm{kg} \\
\text { and succinylcholine } 2 \mathrm{mg} / \mathrm{kg} \text {. No differences were found in time until successful intubation }(\mathrm{I} 56 / 247 \text { seconds). Premedication } \\
\text { with remifentanil attenuated physiologic responses during intubation comparable with those of fentanyl and succinylcholine in } \\
\text { neonates. Intubation conditions were rated more favorably with fentanyl and succinylcholine. Muscular rigidity was observed in the } \\
\text { remifentanil group }(\mathrm{n}=2 / 15) \text {. }\end{array}$ \\
\hline $\begin{array}{l}\text { Hume-Smith } \\
\text { et al }{ }^{65}\end{array}$ & $\begin{array}{l}\left.\text { Remifentanil effective dose-seeking }\left(\mathrm{ED}_{50}\right) \text { study in } 20 \text { neonates and young infants (mean weight } 5.9 \mathrm{~kg}\right) \text {. When coadministered with } \\
\text { glycopyrrolate } 10 \mu \mathrm{g} / \mathrm{kg} \text { and propofol } 5 \mathrm{mg} / \mathrm{kg} \text {, the } \mathrm{ED}_{50} \text { of remifentanil was } 3.1-3.5 \mu \mathrm{g} / \mathrm{kg} \text {. }\end{array}$ \\
\hline $\begin{array}{l}\text { Norman } \\
\text { et } \text { al }^{67}\end{array}$ & $\begin{array}{l}\text { Randomized controlled trial in } 34 \text { preterm neonates (<37 weeks). Atropine/morphine compared with glycopyrrolate, thiopental, } \\
\text { suxamethonium, and remifentanil }(\mathrm{I} \mu \mathrm{g} / \mathrm{kg}) \text {. Intubation score was superior in the remifentanil group [5 (IQR 5-6) to I2 (IQR I0-I3.5)]. } \\
\text { Fluctuations in physiologic variables were more pronounced and prolonged after morphine. }\end{array}$ \\
\hline
\end{tabular}

Abbreviations: InSuRE, Intubation, Surfactant and Rapid Extubation; IQR, interquartile range. 
procedure-related analgosedation. ${ }^{9,62}$ Its good predictability, rapid onset of action, and rapid disappearance are suggested to be advantageous. Clinicians also need to be aware of the potentially rapid development of tolerance, the phenomenon of hyperalgesia, and the potential risk of chest rigidity. ${ }^{69}$

\section{Collaborative initiatives for quality improvement and effective implementation in daily practice}

A promising approach to facilitate implementation of better practices to improve pain management in neonates has been described by Dunbar et al. ${ }^{28}$ Twelve neonatal intensive care units in the Neonatal Intensive Care Quality Improvement Collaboration focused on improving neonatal pain and sedation practices. In essence, these units developed and subsequently implemented evidence-based practices for pain management and sedation in neonates using the EPIQ approach. ${ }^{28,70}$ This strategy emerges as an effective tool for quality improvement within and between neonatal intensive care units, and not limited only to pain management. In essence, this strategy is based on a stepwise approach. First, the group of units introduced changes through plando-study-act cycles and tracked performance measures throughout. Strategies for implementing potentially better practices varied between neonatal intensive care units on the basis of local characteristics. Individual units identified their barriers to implementation, developed tools for improvement, and subsequently shared their experience with the collaborative. Using this approach of collaborative quality improvement techniques enhanced local quality improvement efforts, and resulted in effective implementation of potentially better practices at participating neonatal intensive care units. ${ }^{28}$

Similarly structured initiatives have been reported recently by Zhu et al in Canada and Diendl et al in Austria. ${ }^{71,72}$ Zhu et al reported that knowledge translation initiatives focusing on education, reminders, audit, and feedback had a positive effect on documentation of pain assessment, pain management, pain prevalence, and pain intensity. ${ }^{71} \mathrm{~A}$ similar approach, focusing on care providers and protocol-driven pain management, has been reported by two Austrian neonatal units. ${ }^{73}$ A potentially powerful tool for making progress may be to integrate parents into the health care team, as has been described earlier for facilitated tucking. Taddio et al recently reported on the development of a parent-directed educational pamphlet and video about the management of vaccination-related pain in infancy, and thereby illustrated a valid approach to developing parent-tailored tools. ${ }^{74}$

\section{On contemporary pain management and a clinical research agenda}

Nonpharmacologic and pharmacologic pain management became an indicator of quality of care provided to neonates following the pivotal publications by Anand et al. ${ }^{1}$ In the meantime, neonatal care itself has also evolved towards less invasive care, as reflected by the introduction of minimal enteral feeding to shorten the duration of parenteral nutrition while the duration of endotracheal ventilation is shortened through early nasal continuous positive airway pressure or the InSuRe approach. The emerging data on pain management and shifts in clinical care resulted in the need for a new equipoise. ${ }^{1-10}$ This new equipoise has an impact on contemporary pain management and affects the clinical research agenda. Although to a large extent our subjective opinion, contemporary management relates to the three issues mentioned below, ie, pain management is not a stand-alone activity, needs a structured approach, and new techniques and drugs do potentially result in new (side) effects.

\section{Effective neonatal pain management is not a stand-alone activity}

Effective neonatal pain management should be an integrated part of developmental care. Further evidence of this comes from the finding that improved behavioral outcome in former preterm infants was associated with both the level of developmental care and pain management provided during their neonatal stay. A higher level of developmental care was associated with higher scores for attention and regulation, less excitability, and lower stress scores, while a higher level of neonatal pain management was associated with higher attention and arousal and less lethargy. The association between developmental care and pain management suggests that the combination of both support better neurobehavioral stability. ${ }^{75}$

\section{Structured approach for pain management is needed}

There is no doubt that all neonatal intensive care units need to adapt a validated pain assessment tool and an algorithm outlining the responses of health care providers if abnormal pain scores are detected. This has recently been reillustrated. ${ }^{71-73}$ Reaching consensus within the neonatal intensive care unit care team on interpretation of an abnormal pain score and developing an algorithm of care for each pain scenario is crucially important. The same algorithm should also provide 
pathways for infants who do not respond to treatment or experience adverse events. This structured approach should start with routine use of a validated pain assessment score for the given age group and should be followed by a conditionspecific pain management protocol with a limited number of compounds ("tool box") for which caregivers are aware of (side) effects. Moreover, these pain management protocols should also focus on titration of analgesics, including a decision tree on when and how to increase and decrease exposure to analgesics. $5,9,73$

Until more advanced tools to assess pain become available, we should apply a validated pain assessment tool in clinical practice and train neonatal intensive care unit health care providers in using these tools in a standardized way to guarantee an acceptable variation in assessing neonatal pain. ${ }^{11}$ Although some more sophisticated methods like skin conductance have been suggested, these techniques need further evaluation in different settings before implementation in the clinical setting can be considered. To illustrate this, skin conductance changes not only reflect the stress response, but have also been observed following changes in vital parameters unrelated to pain..$^{76,77}$

\section{New techniques result in new side effects}

Potential new side effects include opioid tolerance, neonatal withdrawal syndrome, hyperalgesia, and drug-related toxicities. Caregivers should familiarize themselves with the contemporary management of these side effects, and any protocol should aim to limit the number of pharmacologic treatment modalities used within any given neonatal intensive care unit. It is better to build experience on the effect and side effect profile of a limited number of compounds, instead of going for a "drug of the month" approach. ${ }^{5,9,73}$

Improvement in current knowledge is obviously needed. This needs to be done based on different types of studies. However, we do suggest that such a clinical research agenda covers the following:

1. Development and validation of more sophisticated pain assessment tools integrating neurobiologic evaluation. At present, we measure at the level of pain expression, which is not equal to nociception or pain perception. ${ }^{11,76,77}$

2. Collection of long-term outcome data after neonatal exposure to analgosedatives is urgently needed, in line with the need for pharmacovigilance regarding other drugs commonly administered to neonates.

3. An appropriate study design is required for neonatal pain studies. It is obvious that pain should be avoided in the design of these studies, necessitating consideration of the "placebo" component of any trial. ${ }^{78,79}$ However, we also need to take potential overdosing into account. Consequently, we encourage clinicians, as well as the ethical committees and other stakeholders involved, to design dose-finding studies, which are needed to improve adequate (effective, neither overexposure nor underexposure) administration of analgosedatives in neonates. The experimental observations in animals concerning neuroapoptosis force us to reconsider the modalities used, including both drugs and the doses administered. Although any study design can be criticized, the report by Ceelie et al on the effect of acetaminophen on postoperative morphine needs in neonates illustrates such a balanced approach in study design. ${ }^{58,80}$

\section{Acknowledgment}

KA is supported by the Fund for Scientific Research, Flanders (Fundamental Clinical Investigatorship 1800214N).

\section{Disclosure}

The authors report no conflicts of interest in this work.

\section{References}

1. Anand KJ, Hickey PR. Pain and its effects in the human neonate and fetus. N Engl J Med. 1987;317(21):1321-1329.

2. Hohmeister J, Kroll A, Wollgarten-Hadamek I, et al. Cerebral processing of pain in school-aged children with neonatal nociceptive input: an exploratory fMRI study. Pain. 2010;150(2):257-267.

3. Walker SM, Franck LS, Fitzgerald M, Myles J, Stocks J, Marlow N. Long-term impact of neonatal intensive care and surgery on somatosensory perception in children born extremely preterm. Pain. 2009; 141(1-2):79-87.

4. Bellieni CV, Iantorno L, Perrone S, et al. Even routine painful procedures can be harmful for the newborn. Pain. 2009;147(1-3):128-131.

5. Allegaert K, Tibboel D, van den Anker J. Pharmacological treatment of neonatal pain: in search of a new equipoise. Semin Fetal Neonatal Med. 2013;18(1):42-47.

6. Davidson AJ. Anesthesia and neurotoxicity to the developing brain: the clinical relevance. Paediatr Anaesth. 2011;21(7):716-721.

7. Soriano SG, Anand KJ, Rovnaghi CR, Hickey PR. Of mice and men: should we extrapolate rodent experimental data to the care of human neonates? Anesthesiology. 2005;102(4):866-868.

8. Durrmeyer X, Vutskits L, Anand KJ, Rimensberger PC. Use of analgesic and sedative drugs in the NICU: integrating clinical trials and laboratory data. Pediatr Res. 2010;67(2):117-127.

9. Thewissen L, Allegaert K. Analgosedation in neonates: do we still need additional tools after 30 years of clinical research? Arch Dis Child Educ Pract Ed. 2011;96(3):112-118.

10. Johnston CC, Fernandes AM, Campbell-Yeo M. Pain in neonates is different. Pain. 2011;152 Suppl 3:S65-S73.

11. Worley A, Fabrizi L, Boyd S, Slater R. Multi-modal pain measurements in infants. J Neurosci Methods. 2012;205(2):252-257.

12. Fabrizi L, Worley A, Patten D, et al. Electrophysiological measurements and analysis of nociception in human infants. J Vis Exp. 2011;58:3118.

13. Van Dijk M, Ceelie I, Tibboel D. Endpoints in pediatric pain studies. Eur J Clin Pharmacol. 2011;67 Suppl 1:61-66. 
14. Allegaert K, Tibboel D. Shouldn't we reconsider procedural techniques to prevent neonatal pain ? Eur J Pain. 2007;11(8):910-912.

15. Ceelie I, van Dijk M, Bax NM, de Wildt SN, Tibboel D. Does minimal access major surgery in the newborn hurt less? An evaluation of cumulative opioid doses. Eur J Pain. 2011;15(6):615-620.

16. Campbell-Yeo M, Fernandes A, Johnston C. Procedural pain management for neonates using nonpharmacological strategies: part 2: mother-driven interventions. Adv Neonatal Care. 2011;11(5): 312-318.

17. Lago P, Garetti E, Merazzi D, et al. Guidelines for procedural pain in the newborn. Acta Paediatr. 2009;98(6):932-939.

18. Ceelie I, de Wildt SN, de Jong M, Ista E, Tibboel D, van Dijk M. Protocolized post-operative pain management in infants: do we stick to it? Eur J Pain. 2012;16(5):760-766.

19. Carbajal R, Rousset A, Danan C, et al. Epidemiology and treatment of painful procedures in neonates in intensive care units. JAMA. 2008;300(1):60-70.

20. Simons SH, van Dijk M, Anand KS, Roofthooft D, van Lingen RA, Tibboel D. Do we still hurt newborn babies? A prospective study of procedural pain and analgesia in neonates. Arch Pediatr Adolesc Med. 2003;157(11):1058-1064.

21. Lago P, Garetti E, Boccuzzo G, et al. Procedural pain in neonates: the state of the art in the implementation of national guidelines in Italy. Paediatr Anaesth. 2013;23(5):407-414.

22. Lago P, Boccuzzo G, Garetti E, et al. Pain management during invasive procedures at Italian NICUs: has anything changes in the last five years. J Matern Fetal Neonatal Med. 2013;26(3):303-305.

23. Losacco V, Cuttini M, Greisen G, et al. Heel blood sampling in European neonatal intensive care units: compliance with pain management guidelines. Arch Dis Child. 2011;96(1):F65-F68.

24. Gradin M, Eriksson M; NeoOpioid Investigators Group. Neonatal pain assessment in Sweden - a fifteen-year follow up. Acta Paediatr. 2011;100(2):204-208.

25. Larsson BA, Tannfeldt G, Lagercrantz H, Olsson GL. Venipuncture in more effective and less painful than heel lancing for blood tests in neonates. Pediatrics. 1998;101(5):882-886.

26. Ogawa S, Ogihara T, Fujiwara E, et al. Venepuncture is preferable to heel lance for blood sampling in term neonates. Arch Dis Child Fetal Neonatal Ed. 2005;90(5):F432-F436.

27. Cordero L, Sananes M, Ayers LW. Mechanically ventilated newborns: a comparison of two airway suctioning regimens. Pediatr Res. 1998;43(Suppl 4):210

28. Dunbar AE 3rd, Sharek PJ, Mickas NA, et al. Implementation and casestudy results of potentially better practices to improve pain management of neonates. Pediatrics. 2006;118 Suppl 2:S87-S94.

29. Cordero L, Sananes M, Ayers LW. A comparison of two airway suctioning frequencies in mechanically ventilated, very-low-birthweight infants. Respir Care. 2001;46(8):783-788.

30. Taylor JE, Hawley G, Flenady V, Woodgate PG. Tracheal suctioning without disconnection in intubated ventilated neonates. Cochrane Database Syst Rev. 2011;12:CD003065.

31. Cone S, Pickler RH, Grap MJ, McGrath J, Wiley PM. Endotracheal suctioning in preterm infants using four-handed versus routine care. J Obstet Gynecol Neonatal Nurs. 2013;42(1):92-104.

32. Gillies D, Spence K. Deep versus shallow suction of endotracheal tubes in ventilated neonates and young infants. Cochrane Database Syst Rev. 2011;7:CD003309.

33. Naughton KA. The combined use of sucrose and nonnutritive sucking for procedural pain in both term and preterm neonates: an integrative review of the literature. Adv Neonatal Care. 2013;13(1):9-19.

34. Carbajal R, Chauvet X, Couderc S, Olivier-Martin M. Randomised trial of analgesic effects of sucrose, glucose, and pacifiers in term neonates. BMJ. 1999;319(7222):1393-1397.

35. Bueno M, Yamada J, Harrison D, et al. A systematic review and metaanalyses of nonsucrose sweet solutions for pain relief in neonates. Pain Res Manag. 2013;18(3):153-161.
36. Stevens B, Yamada J, Lee GY, Ohlsson A. Sucrose for analgesia in newborn infants undergoing painful procedures. Cochrane Database Syst Rev. 2013;1:CD001069.

37. Marin Gabriel MA, Del Rey Hurtado de Mendoza B, Jiménez Figueroa L, et al. Analgesia with breastfeeding in addition to skinto-skin contact during heel prick. Arch Dis Child Fetal Neonatal Ed. 2013;98(6):F499-F503.

38. Prasopkittikun T, Tilokskulchai F. Management of pain form heel stick in neonates: an analysis of research conducted in Thailand. $J$ Perinat Neonat Nurs. 2003;17(4):304-312.

39. Corff KE, Seideman R, Venkataraman PS, Lutes L, Yates B. Facilitated tucking: a nonpharmacologic comfort measure for pain in preterm neonates. J Obstet Gynecol Neonatal Nurs. 1995;24(2):143-147.

40. Fearon I, Kisilevsky BS, Mains SM, Muir DW, Tranmer J. Swaddling after heel lance: age-specific effects on behavioral recovery in preterm infants. J Dev Behav Pediatr. 1997;18(4):222-232.

41. Ward-Larson C, Horn RA, Gosnell F. The efficacy of facilitated tucking for relieving procedural pain of endotracheal suctioning in very low birth weight infants. MCN Am J Matern Child Nurs. 2004;29(3):151-156.

42. Hill S, Engle S, Jorgensen J, Kralik A, Whitman K. Effects of facilitated tucking during routine care of infants born preterm. Pediatr Phys Ther. 2005;17(2):158-163.

43. Axelin A, Salanterä S, Lehtonen L. 'Facilitated tucking by parents' in pain management of preterm infants - a randomized crossover trial. Early Hum Dev. 2006;82(4):241-247.

44. Liaw JJ, Yang L, Katherine Wang KW, Chen CM, Chang YC, Yin T. Non-nutritive sucking and facilitated tucking relieve preterm infant pain during heel-stick procedures: a prospective, randomised controlled crossover trial. Int J Nurs Stud. 2012;49(3):300-309.

45. Cignacco EL, Sellam G, Stoffel L, et al. Oral sucrose and 'facilitated tucking' for repeated pain relief in preterms: a randomized controlled trial. Pediatrics. 2012;129(2):299-308.

46. Liaw JJ, Yang L, Lee CM, Fan HC, Chang YC, Cheng LP. Effects of combined use of non-nutritive sucking, oral sucrose, and facilitated tucking on infant behavioural states across heel-stick procedures: a prospective, randomised controlled trial. Int J Nurs Stud. 2013;50(7): 883-894.

47. Sundaram B, Shrivatava S, Pandian JS, Singh VP. Facilitated tucking on pain in pre-term newborns during neonatal intensive care: a single blinded randomized controlled cross-over pilot trial. J Pediatr Rehabil Med. 2013;6(1):19-27.

48. Gerull R, Cignacco E, Stoffel L, Sellam G, Nelle M. Physiological parameters after nonpharmacological analgesia in preterm infants: a randomized trial. Acta Paediatr. 2013;102(8):e368-e373.

49. Bellieni CV, Tei M, Coccina F, Buonocore G. Sensorial saturation for infants' pain. J Matern Fetal Neonatal Med. 2012;25 Suppl 1:79-81.

50. Su F, Hammer GB. Dexmedetomidine: pediatric pharmacology, clinical uses and safety. Expert Opin Drug Saf. 2011;10(1):55-66.

51. Dilek O, Yasemin G, Atci M. Preliminary experience with dexmedetomidine in neonatal anaesthesia. J Anaesth Clin Pharmacol. 2011;27(1):17-22.

52. Schnabel A, Reichl SU, Poepping DM, Kranke P, Pogatzki-Zahn EM, Zahn PK. Efficacy and safety of intraoperative dexmedetomidine for acute postoperative pain in children: a meta-analysis of randomized controlled trials. Paediatr Anaesth. 2013;23(2):170-179.

53. Lam F, Bhutta AT, Tobias JD, Gossett JM, Morales L, Gupta P. Hemodynamic effects of dexmedetomidine in critically ill neonates and infants with heart disease. Pediatr Cardiol. 2012;33(7):1069-1077.

54. Su F, Nicolson SC, Gastonguay MR, et al. Population pharmacokinetics of dexmedetomidine in infants after open heart surgery. Anesth Analg. 2010;110(5):1383-1392.

55. Van den Anker JN, Tibboel D. Pain relief in neonates: when to use intravenous paracetamol? Arch Dis Child. 2011;96(6):573-574.

56. Gibb IA, Anderson BJ. Paracetamol (acetaminophen) pharmacodynamics: interpreting the plasma concentration. Arch Dis Child. 2009;93(3):241-247. 
57. Allegaert K, Naulaers G, Vanhaesebrouck S, Anderson BJ. The paracetamol concentration-effect relation in neonates. Paediatr Anaesth. 2013;23(1):45-50

58. Ceelie I, de Wildt SN, van Dijk M, et al. Effect of intravenous paracetamol on postoperative morphine requirements in neonates and infants undergoing major noncardiac surgery: a randomized controlled trial. JAMA. 2013;309(2):149-154.

59. Shah V, Taddio A, Ohlsson A. Randomised controlled trial of paracetamol for heel prick pain in neonates. Arch Dis Child Fetal Neonatal Ed. 1998;79(3):F209-F211.

60. Van Lingen RA, Quak CM, Deinum HT, et al. Effects of rectally administered paracetamol on infants delivered by vacuum extraction. Eur J Obstet Gynecol Reprod Biol. 2001;94(1):73-78.

61. Tinner EM, Hoesli I, Jost K, et al. Rectal paracetamol in newborn infants after assisted vaginal delivery may increase pain response. $J$ Pediatr. 2013;162(1):62-66.

62. Penido MG, Garra R, Sammartino M, Pereira e Silva Y. Remifentanil in neonatal intensive care and anaesthesia practice. Acta Paediatr. 2010; 99(10):1454-1463.

63. Pereira e Silva Y, Gomez RS, Marcatto Ide O, Maximo TA, Barbosa RF, Simoes e Silva AC. Morphine versus remifentanil for intubating preterm neonates. Arch Dis Child Fetal Neonatal Ed. 2007;92(4): F293-F294.

64. Welzing L, Kribs A, Huenseler C, Eifinger F, Mehler K, Roth B. Remifentanil for INSURE in preterm infants: a pilot study for evaluation of efficacy and safety aspects. Acta Paediatr. 2009;98(9): 1416-1420.

65. Choog K, AlFaleh K, Doucette J, et al. Remifentanil for endotracheal intubation in neonates: a randomised controlled trial. Arch Dis Child Fetal Neonatal Ed. 2010;95(2):F80-F84.

66. Hume-Smith J, Mc Cormack, Montgomery C, et al. The effect of age on the dose of remifentanil for tracheal intubation in infants and children. Paediatr Anaesth. 2010;20(1):19-27.

67. Norman E, Wikström S, Hellström-Westas L, Turpeinen U, Hämäläinen E, Fellman V. Rapid sequence induction is superior to morphine for intubation of preterm infants: a randomized controlled trial. J Pediatr. 2011;159(6):893.e1-899.e1.

68. Lago P, Tiozzo C, Buccuzzo G, Allegro A, Zacchello F. Remifentanil for percutaneous intravenous central catheter placement in preterm infants: a randomized controlled trial. Paediatr Anaesth. 2008;18(8):736-744.
69. Allegaert K, Thewissen L, van den Anker JN. Remifentanil in neonates: a promising compound in search of its indications? Pediatr Neonatol. 2012;53(6):387-388.

70. Cronin CM, Baker GR, Lee SK, Ohlsson A, McMillan DD, Seshia MM. Canadian Neonatal Network EPIQ Study Group. Reflections on knowledge translation in Canadian NICUs using the EPIQ method. Healthc Q. 2011;14(3):8-16.

71. Johnston C, Barrington KJ, Taddio A, Carbajal R, Filion F. Pain in Canadian NICUs: have we improved over the past 12 years? Clin J Pain. 2011;27(3):225-232.

72. Zhu LM, Stinson J, Palozzi L, et al. Improvements in pain outcomes in a Canadian pediatric teaching hospital following implementation of a multifaceted knowledge translation initiative. Pain Res Manag. 2012;17(3):173-179.

73. Deindl P, Unterasinger L, Kappler G, et al. Successful implementation of a neonatal pain and sedation protocol at 2 NICUs. Pediatrics. 2013; 132(1):e211-e218

74. Taddio A, Shah V, Leung E, et al. Knowledge translation of the HELPinKIDS clinical practice guideline for managing childhood vaccination pain: usability and knowledge uptake of educational materials directed to new parents. BMC Pediatr. 2013;13:23.

75. Montirosso R, del Prete, Bellu R, et al. Level of NICU quality of developmental care and neurobehavioral performance in very preterm infants. Pediatrics. 2012;129(5):e1129-e1137.

76. Storm H. Skin conductance and the stress response from heel stick in preterm infants. Arch Dis Child Fetal Neonatal Ed. 2000;83(2): F143-F147.

77. Valkenburg AJ, Niehof SP, van Dijk M, Verhaar EJ, Tibboel D. Skin conductance peaks could result from changes in vital parameters unrelated to pain. Pediatr Res. 2012;71(4 Pt 1):375-379.

78. Bellieni CV, Taddio A, Linebarger JS, Lantos JD. Should an IRB approve a placebo-controlled randomized trial of analgesia for procedural pain in neonates? Pediatrics. 2012;130(3):550-553

79. Weimer K, Gulewitsch MD, Schwille-Kiuntke J, Klosterhalfen S, Enck P. Placebo effects in children: a review. Pediatr Res. 2013;74(1):96-102.

80. Anand KJ. Pain panacea for opiophobia in infants? JAMA. 2013;309(2) 183-184.
Research and Reports in Neonatology

\section{Publish your work in this journal}

Research and Reports in Neonatology is an international, peer-reviewed, open access journal publishing original research, reports, editorials, reviews and commentaries on neonatal health. The manuscript management system is completely online and includes a very quick and fair

\section{Dovepress}

peer-review system. Visit http://www.dovepress.com/testimonials.php to read real quotes from published authors. 